\title{
Role of Invading Leukocytes in Enhanced Atrial Eicosanoid Production following Rabbit Left Ventricular Myocardial Infarction
}

\author{
Mark S. Freed, Philip Needleman, “ Carol G. Dunkel,‡ Jeffrey E. Saffitz, \\ Departments of Medicine/Cardiology, ${ }^{*}$ Pharmacology, ${ }^{\ddagger}$ Anesthesiology, and ${ }^{\S}$ Pathology, Washington University School of Medicine, \\ St. Louis, Missouri 63110
}

\begin{abstract}
The isolated perfused hearts of rabbits previously subjected to in vivo left ventricular myocardial infarction (LVMI) show a 5-10-fold increase in $f$-Met-Leu-Phe (FMLP) and bradykinin (BK)-stimulated eicosanoid metabolite production relative to noninfarcted hearts. This exaggerated arachidonate metabolism has been shown to occur primarily in the cardiac atria, a site remote from the zone of injury and to be associated with a 10-15-fold increase in atrial FMLP receptor number in the absence of atrial inflammation. All of these changes were temporally related to leukocyte infiltration into the infarct zone. To determine whether invading leukocytes mediate these responses, acute inflammatory cell influx was suppressed either by inducing leukopenia with nitrogen mustard or by administration of BW-755C, a mixed cyclooxygenase-lipoxygenase inhibitor. Both pharmacological manipulations resulted in a decrease in inflammatory cells in the infarct zone and a marked suppression (50-70\%) of ex vivo agonist-stimulated eicosanoid metabolite production from perfused hearts and isolated atria. These manipulations also resulted in reversal of ex vivo FMLP-induced coronary vasoconstriction as well as augmentation of BK-induced coronary vasodilation. Further studies in nitrogen mustard-treated animals revealed a suppression of the LVMI-stimulated increase in atrial FMLP receptor number. These data show that suppression of leukocyte invasion after LVMI attenuates enhanced cardiac and atrial eicosanoid metabolite production, and results in marked changes in coronary vascular reactivity. An additional finding was that basal and stimulated LTB $_{4}$ production was markedly increased in infarcted hearts. In vivo suppression of the increase in $\mathbf{L T B}_{4}$ production by BW-755C was associated with inhibition of inflammatory cell influx into the infarct zone. It therefore appears that $\mathrm{LTB}_{4}$ may be an important proinflammatory mediator of leukocyte invasion after LVMI.
\end{abstract}

\section{Introduction}

The isolated buffer perfused hearts of rabbits previously subjected to in vivo left ventricular myocardial infarction (LVMI) demonstrate a 5-10-fold increase in the production

Address reprint requests to Dr. Needleman, Department of Pharmacology, Washington University School of Medicine, St. Louis, MO 63110.

Received for publication 22 February 1988 and in revised form 25 August 1988

1. Abbreviations used in this paper: BK, bradykinin; LT, leukotriene; LVMI, left ventricular myocardial infarction.

J. Clin. Invest.

(c) The American Society for Clinical Investigation, Inc.

$0021-9738 / 89 / 01 / 0205 / 08 \quad \$ 2.00$

Volume 83, January 1989, 205-212 of $\mathrm{PGE}_{2}$, prostacyclin, and $\mathrm{TXA}_{2}$ when stimulated with the chemotactic peptide $n$-formyl-methionyl-leucyl-phenylalanine (FMLP) or bradykinin (BK) relative to noninfarcted hearts (1). Surprisingly, much of the enhanced prostanoid synthesis was shown to occur in the atria, a site remote from the zone of injury (2), and was associated with a 10-15-fold increase in atrial FMLP receptor number in the absence of atrial inflammation (Dunkel, C. G., J. E. Saffitz, and A. S. Evers. Submitted for publication.). Furthermore, when compared to noninfarcted control animals, the isolated perfused hearts of infarcted animals demonstrated an exaggerated FMLP-induced coronary vasoconstriction which was peptidoleukotriene-mediated and confined exclusively to the right atrium, as well as a BK-induced PG-mediated coronary vasodilation $(1,2)$.

In these previous experiments, a temporal relationship was observed between enhanced eicosanoid synthesis and inflammatory cell influx into the infarct zone. We therefore hypothesized that leukocyte influx might be required for enhanced arachidonate metabolism after LVMI. Further support for the relationship between leukocyte invasion into injured tissue and exaggerated eicosanoid synthesis is found in previous work in the hydronephrotic kidney, a model of renal inflammation. In these studies, exaggerated renal eicosanoid production was suppressed when inflammatory cell influx was inhibited by nitrogen mustard treatment before unilateral ureteral obstruction (3). Release of the ureteral obstruction also resulted in a rapid disappearance of inflammatory cells from the kidney and a return of eicosanoid production towards normal (4).

To determine whether invading leukocytes mediate the LVMI-induced augmentation in eicosanoid production, acute inflammatory cell influx was suppressed either by inducing leukopenia with nitrogen mustard or by administration of BW-755C, a mixed cyclooxygenase-lipoxygenase inhibitor previously shown to inhibit inflammatory cell influx in canine LVMI (5). These studies demonstrate that suppression of leukocyte invasion inhibits exaggerated cardiac and atrial eicosanoid production that follows LVMI and results in dramatic changes in coronary vascular reactivity.

\section{Methods}

\section{Materials}

Bradykinin was purchased from Boehringer-Mannheim (Indianapolis, IN), and A23187, FMLP, and mechlorethamine were purchased from Sigma Chemical Co. (St. Louis, MO). Leukotriene (LT) $\mathrm{C}_{4}$ and $\mathrm{LTB}_{4}$ standards were a gift of J. Rokach (Merck-Frost Canada, Inc., Pointe Clair-Dorval, Quebec, Canada) and the prostaglandin standards were a gift of Dr. J. Pike of the Upjohn Co. (Kalamazoo, MI). $\left[{ }^{3} \mathrm{H}\right] 6-$ keto prostaglandin $\mathrm{F}_{1 \alpha}(160 \mathrm{Ci} / \mathrm{mM}),\left[{ }^{125} \mathrm{I}\right] \mathrm{NaI}$, and NCS tissue solubilizer were obtained from Amersham Corp. (Arlington Heights, IL); $\left[{ }^{3} \mathrm{H}\right]-$ $\mathrm{LTC}_{4}(40 \mathrm{Ci} / \mathrm{mmol}),\left[{ }^{3} \mathrm{H}\right] \mathrm{FMLP}(60 \mathrm{Ci} / \mathrm{mmol})$ and $\left[{ }^{3} \mathrm{H}\right] \mathrm{LTB}_{4}(178$ $\mathrm{Ci} / \mathrm{mmol}$ ) were purchased from New England Nuclear (Boston, MA). $\mathrm{LTC}_{4}$ antiserum and BW-755C were a gift from R. Bell (Riker Laboratories, St. Paul, MN), and 6-keto-prostaglandin $F_{1 \alpha}\left(6-k e t o ~ P G F_{1 \alpha}\right)$ 
antibody was kindly supplied by $R$. Fertel (Ohio State University, Department of Pharmacology, Columbus, $\mathrm{OH}$ ).

\section{Surgical myocardial infarction}

Male New Zealand white rabbits (2-3 kg) were subjected to in vivo LVMI consisting of $60 \mathrm{~min}$ of left circumflex coronary artery occlusion followed by reperfusion as previously described (1). Briefly, after pentobarbital anesthesia ( $35 \mathrm{mg} / \mathrm{kg}$ i.v.), a tracheostomy was performed, the rabbits were ventilated with $100 \%$ oxygen, and the hearts were exposed through a transverse thoracotomy. After pericardiotomy, a 5-0 Prolene suture was placed under the distal left circumflex coronary artery and tied over a piece of polyethylene tubing (PE-50; ClayAdams Div., Becton-Dickenson and Co., Parsippany, NJ) placed parallel to the vessel. Myocardial ischemia was evident upon tightening the ligature by the appearance of a wedge-shaped anemic zone. After $60 \mathrm{~min}$, reperfusion was achieved by sliding the PE-50 tubing from underneath the ligature, manifested by a cherry red hyperemia in the previously bland wedge of ischemic myocardium. The thoracotomy was then closed in layers, the tracheostomy repaired, and the animals allowed to convalesce.

\section{Heart perfusion}

1 or $2 \mathrm{~d}$ after surgery, the animals were reanesthetized and heparinized $(1,000 \mathrm{U}$ i.v.). The hearts were excised and the aortas were quickly suspended from a perfusion apparatus. The aorta was then perfused in a retrograde fashion resulting in the delivery of oxygenated $\left(\mathrm{O}_{2} / \mathrm{CO}_{2}\right.$, 95\%:5\%) Krebs-Henseleit buffer $\left(\mathrm{NaCl} 120 \mathrm{mM}, \mathrm{KCl} 4.7 \mathrm{mM}, \mathrm{MgSO}_{4}\right.$ $1.2 \mathrm{mM}, \mathrm{CaCl}_{2} 2.5 \mathrm{mM}, \mathrm{KH}_{2} \mathrm{PO}_{4} 1.2 \mathrm{mM}, \mathrm{NaHCO}_{3} 25 \mathrm{mM}$, dextrose $10 \mathrm{mM}$ ) at $37^{\circ} \mathrm{C}$ and a constant flow rate of $25 \mathrm{ml} / \mathrm{min}$ to the coronary arteries. This promptly resulted in a spontaneously beating preparation with a mean basal coronary perfusion pressure of $50 \pm 6 \mathrm{mmHg}$. Changes in perfusion pressure were monitored via a sidearm in the perfusion apparatus using a pressure transducer (P23db; Statham, Inc., Oxnard, CA) and a brush recorder (model 440; Gould, Inc., Santa Clara, CA). After a 30-min equilibration period, cardiac effluent was collected for $5 \mathrm{~min}$ before and after stimulations with bolus intracoronary administration of FMLP (100 ng) or BK $(1 \mu \mathrm{g})$ via an injection port $12 \mathrm{~cm}$ above the aorta. These doses were shown to elicit maximal eicosanoid production from infarcted hearts (1). A 1-ml aliquot of effluent was stored at $-20^{\circ} \mathrm{C}$ until quantitated for prostaglandins, thromboxane, and $\mathrm{LTB}_{4}$ by RIA, and the remainder of the collection sample was extracted for $\mathrm{LTC}_{4}$ as described below. Leukotrienes were not measured after bradykinin administration as previous studies failed to demonstrate stimulated release (1).

To prepare isolated atria, the heart was placed in iced Krebs-Henseleit buffer following cardiac perfusion. The atria were removed and suspended under $1 \mathrm{~g}$ of tension in a tissue bath containing $20 \mathrm{ml}$ of oxygenated $\left(\mathrm{O}_{2}: \mathrm{CO}_{2}, 95: 5 \%\right) \mathrm{Krebs}-\mathrm{Henseleit}$ buffer at $37^{\circ} \mathrm{C}$. These preparations spontaneously beat at a rate of $\sim 150$ per minute. The buffer in the tissue bath was changed every $10 \mathrm{~min}$ for $30 \mathrm{~min}$. At this time buffer was collected after either a 5-min control period, or a 5-min exposure to either FMLP $(100 \mathrm{ng})$ or BK $(1 \mu \mathrm{g})$. A 20 -min recovery period was allowed between agonist stimulations. A $1-\mathrm{ml}$ aliquot of the bath buffer was saved $\left(-20^{\circ} \mathrm{C}\right)$ for thromboxane RIA.

\section{$R I A$}

RIA analyses of 6-keto- $\mathrm{PGFl}_{\alpha}$ (a stable metabolite of prostacyclin), $\mathrm{PGE}_{2}$, and thromboxane $\mathrm{B}_{2}$ (a stable metabolite of $\mathrm{TXA}_{2}$ ) were performed as previously described $(6,7)$. RIA for $\operatorname{LTB}_{4}(8)$ and $\mathrm{LTC}_{4}$ was performed as previously described. The cross-reactivities of the $\mathrm{PGE}_{2}$, 6-keto- $\mathrm{PGFl}_{\alpha}, \mathrm{TXB}_{2}$, and $\mathrm{LTC}_{4}$ antisera have been previously described (1). Extraction of $\mathrm{LTC}_{4}$ for RIA consisted of applying the $125-\mathrm{ml}$ sample (acidified to $\mathrm{pH} 6.2$ with $\mathrm{HCl}$ ) to a preactivated $\mathrm{C}-18$ octadecylsilyl column (J. T. Baker Chemical Co., Phillipsburg, NJ). The column was washed with water and the products were eluted with $5 \mathrm{ml}$ of $100 \%$ methanol. Recovery, as determined from extractable $\left[{ }^{3} \mathrm{H}\right] \mathrm{LTC}_{4}$ from $125 \mathrm{ml}$ buffer samples, was $80 \pm 6 \%(n=4)$.

\section{Histology}

After ex vivo cardiac perfusion experiments, transmural slices of the heart were prepared to include both infarcted and normal myocardium and then fixed in 10\% phosphate-buffered formalin. Tissue was processed conventionally for light microscopy and sectioned at $5 \mu \mathrm{m}$. Sections were stained with hematoxylin and eosin and examined by light microscopy. To determine the extent of inflammatory cell influx, multiple areas of transmural sections were examined from two or more slices of at least three animals in control and experimental groups.

\section{FMLP receptor binding studies}

1 or $2 \mathrm{~d}$ after coronary artery occlusion, hearts from anesthetized and heparinized animals were removed and retrogradely perfused via an aortic cannula with $20 \mathrm{ml}$ of ice-cold saline to remove blood from the vasculature. Atria were frozen over dry ice, sectioned at $12 \mu \mathrm{m}$ with a cryostat $\left(-20^{\circ} \mathrm{C}\right)$, mounted on gelatin-coated slides and stored overnight at $-20^{\circ} \mathrm{C}$. Binding isotherms were performed by incubating tissue sections at $25^{\circ} \mathrm{C}$ for $30 \mathrm{~min}$ in buffer containing increasing concentrations $(0.3-15 \mathrm{~nm})$ of ${ }^{3} \mathrm{H}$-FMLP in the presence or absence of 100 -fold unlabeled ligand ( $30 \mathrm{~nm}-1.5 \mu \mathrm{m}$ FMLP). To halt binding and remove unbound ligand, sections were washed in ice-cold buffer for 5 min, allowed to dry under a stream of air, and prepared for scintillation spectrometry. $B_{\max }$ values were calculated from Scatchard analysis of binding isotherm data.

\section{Assessment of in vivo cyclooxygenase and lipoxygenase inhibition}

To validate the in vivo efficacy of BW-755C, a whole blood assay was performed to determine cyclooxygenase and lipoxygenase activity as previously described (9). In brief, blood was drawn from the marginal ear vein of each animal before and after BW-755C administration. The sample was collected in a plastic test tube containing 0.1 volumes percent of heparin $(1,000 \mathrm{U} / \mathrm{ml})$ and placed in a water bath at $37^{\circ} \mathrm{C}$. After a 2-min equilibration period, the calcium ionophore A23187 was added to the blood sample to stimulate eicosanoid production (final concentration $20 \mu \mathrm{g} / \mathrm{ml}$ ). After a 5-min stimulation, the reaction was terminated by centrifugation (3,000 $\mathrm{g}$ for $1 \mathrm{~min})$, and the plasma was collected and stored at $-20^{\circ} \mathrm{C}$. Cyclooxygenase and lipoxygenase activity was estimated from $\mathrm{TXB}_{2}$ and $\mathrm{LTB}_{4}$ quantitation (RIA), respectively. Each experimental animal was subjected to stimulations before administration of BW-755C, and at 12 and $24 \mathrm{~h}$ after coronary reperfusion.

\section{Guinea pig ileum assay}

To demonstrate reversible inhibition of cardiac lipoxygenase by BW-755C, a guinea pig ileum strip was superfused by coronary venous effluent from an ex vivo buffer perfused rabbit heart to detect peptidoleukotrienes. Contractions were recorded in response to authentic $\mathrm{LTD}_{4}$ (standardization), FMLP, and BK administered directly to the tissue or through the heart in the presence of BW-755C or FPL-55712, a peptidoleukotriene antagonist.

\section{Experimental protocol}

Nitrogen mustard. Male New Zealand white rabbits received an initial bolus dose of mechlorethamine $(1.75 \mathrm{mg} / \mathrm{kg}$ in sterile $0.9 \% \mathrm{NaCl}$ i.v.) and subsequent doses of the nitrogen mustard $(1 \mathrm{mg} / \mathrm{kg})$ on the following $2 \mathrm{~d}$. $24 \mathrm{~h}$ after the last dose, LVMI surgery was performed. All animals were prepared for cardiac perfusion experiments $48 \mathrm{~h}$ postoperatively. Total leukocyte counts (improved Neubauer chamber) and differential cell counts (Wright stain) were determined before surgery and at the time of sacrifice. Only those animals manifesting and maintaining leukopenia $\left(<1,000 / \mathrm{mm}^{3}\right.$ whole blood) were used for ex vivo cardiac perfusion and isolated atrial experiments.

$B W-755 C$. Animals received BW-755C $(25 \mathrm{mg} / \mathrm{kg}$ in $0.4 \mathrm{ml}$ DMSO i.v. over $1 \mathrm{~min}) 1 \mathrm{~h}$ before and $\sim 8$ and $16 \mathrm{~h}$ after coronary artery occlusion. All animals were prepared for cardiac perfusion and isolated 
atrium experiments $24 \mathrm{~h}$ postoperatively. Whole blood stimulations with the calcium ionophore A23187 were performed to confirm the in vivo inhibition of cyclooxygenase and lipoxygenase enzymes as described above.

Controls. Surgical LVMI was performed in control animals receiving neither mechlorethamine nor BW-755C. Animals were allowed to convalesce for 1 or $2 \mathrm{~d}$ after $\mathbf{l}$ h of in vivo coronary artery occlusion. Thereafter, ex vivo cardiac perfusion and isolated atrium experiments were performed. To determine the effects of nitrogen mustard alone on agonist-stimulated cardiac eicosanoid production, nonoperated animals were rendered leukopenic with mechlorethamine and subjected to cardiac perfusion studies.

\section{Results}

\section{Nitrogen mustard experiments}

Animals were rendered leukopenic before surgical LVMI to suppress leukocyte influx into the infarct zone. Thereafter, eicosanoid production during ex vivo cardiac perfusion and isolated atrium experiments was quantitated, atrial FMLP receptor binding studies were performed, and coronary perfusion pressure changes were recorded to examine the effects of invading leukocytes on these parameters.

To confirm the in vivo efficacy of mechlorethamine, total and differential leukocyte counts were performed before and after drug treatment. Nitrogen mustard administration resulted in a marked reduction in circulating leukocytes (control $5,760 \pm 700 / \mathrm{mm}^{3}$ of whole blood, $n=5$, vs. nitrogen mustard treatment $700 \pm 50 / \mathrm{mm}^{3}, n=4, P<0.05$ ) with $\mathrm{PMN}$ preferentially suppressed (PMN $>95 \%$ inhibition, mononuclear leukocytes $\approx 60 \%$ ).

Histology. Histological analysis of control 2-d reperfused hearts previously subjected to $1 \mathrm{~h}$ of distal left circumflex coronary artery occlusion demonstrated transmural left ventricular myocardial infarction (Fig. $1 a$ ). Numerous inflammatory cells were seen throughout the infarcted tissue and consisted primarily of mononuclear cells (macrophages and lymphocytes) with PMNs occasionally observed. In contrast, the hearts of those animals treated with nitrogen mustard before surgical LVMI demonstrated a dramatic reduction in inflammatory cell influx. Despite large areas of transmural infarction, only rare mononuclear leukocytes or PMNs were observed in any experimental animal (Fig. $1 b$ ).

Eicosanoid production. Rendering animals leukopenic before surgical LVMI results in not only dramatic inhibition of inflammatory cell influx into the infarct zone, but also in marked suppression of agonist-stimulated eicosanoid production in cardiac perfusion experiments. As summarized in Table I, nitrogen mustard pretreatment resulted in greatly diminished FMLP-stimulated eicosanoid production measured from perfused hearts: $\mathrm{PGE}_{2}$ (73\% reduction when compared to control hearts of 2-d infarcted animals), 6-keto-PGFl ${ }_{\alpha}(67 \%)$, $\mathrm{TXB}_{2}(91 \%)$, and leukotrienes $\mathrm{B}_{4}(56 \%)$ and $\mathrm{C}_{4}(84 \%)$. Bradykinin-induced $\mathrm{PGE}_{2}$ and $\mathrm{TXB}_{2}$ production from nitrogen mustard treated animals were suppressed as well (56 and $84 \%$ reductions, respectively). These results were not due to toxic effects of nitrogen mustard, as mechlorethamine administration to nonoperated animals had no effect on agonist-stimulated cyclooxygenase or lipoxygenase product formation (data not shown).

Isolated atria. Previous work has demonstrated that the right atrium is responsible for much of the enhanced eicosan- oid production after LVMI. In this regard, following LVMI, there was an approximately eight-fold increase in atrial $\mathrm{TXB}_{2}$ release (2). In the current study, we therefore used $\mathrm{TXB}_{2}$ release from isolated atria as a marker for the exaggerated atrial eicosanoid synthesis after LVMI. As summarized in Table I, using isolated atria from animals treated with nitrogen mustard, FMLP and BK-induced $\mathrm{TXB}_{2}$ production was greatly diminished (79 and $72 \%$ reductions from control $2-\mathrm{d}$ infarcts, respectively). It therefore appears that nitrogen mustard treatment not only suppresses total agonist-stimulated cardiac eicosanoid production, but specifically inhibits the exaggerated atrial eicosanoid production that follows LVMI.

Atrial FMLP receptor expression. Previously, it was demonstrated that the enhanced FMLP-stimulated atrial eicosanoid production after LVMI was associated with a marked increase in FMLP receptor number (Dunkel, C. G., J. E. Saffitz, and A. S. Evers. Submitted for publication.). To determine whether the decrease in atrial arachidonate metabolism following nitrogen mustard treatment was mediated by an alteration in FMLP receptor expression, binding studies were performed using ${ }^{3} \mathrm{H}$-FMLP. As seen in Table II, 1 or $2 \mathrm{~d}$ after coronary reperfusion, there is a 10-15-fold increase in atrial FMLP receptor number. However, the hearts of animals treated with nitrogen mustard demonstrated a marked suppression of the LVMI-stimulated increase in atrial FMLP receptor number, suggesting a possible mechanism for the attenuated FMLPstimulated eicosanoid production seen in this experimental group.

Coronary resistance changes. Coronary vascular resistance changes following intracoronary agonist administration during ex vivo cardiac perfusion studies are presented in Fig. 2. FMLP $(100 \mathrm{ng})$ administration to hearts of control 2-d infarcted animals resulted in coronary vasoconstriction $(27 \pm 3 \%$ increase in perfusion pressure over baseline, $n=7$ ). However, when given to the hearts of 2-d infarcted animals treated with nitrogen mustard, FMLP caused a marked coronary vasodilation $(40 \pm 8 \%$ decrease in perfusion pressure from baseline, $n=4)$. Furthermore, BK administration to hearts of animals receiving nitrogen mustard greatly augmented coronary vasodilation shown to occur in $2 \mathrm{~d}$ infarcted hearts (control $2 \mathrm{~d}$ infarct $32 \pm 3 \%$ decrease in perfusion pressure from baseline, $n=5$, vs. nitrogen mustard $2 \mathrm{~d}$ infarct $54 \pm 8 \%, n=4, P<0.05$ ). Baseline coronary perfusion pressures were similar in control and experimental groups $(50 \pm 6 \mathrm{mmHg})$.

In summary, nitrogen mustard administration before coronary artery occlusion: $(a)$ dramatically inhibits inflammatory cell influx into the infarct zone; $(b)$ results in a marked suppression of agonist-stimulated eicosanoid production in both the isolated heart and atria; $(c)$ inhibits the LVMI-stimulated increase in atrial FMLP receptor number; $(d)$ reverses FMLPinduced coronary vasoconstriction and augments BK-induced coronary vasodilation.

\section{$B W-755 C$ experiments}

In these experiments BW-755C was used to suppress leukocyte invasion into LVMI. BW-755C has been previously shown to retard acute inflammatory cell influx in experimental canine myocardial infarction (5). BW-755C is conjectured to work by inhibiting the synthesis of proinflammatory eicosanoids and secondarily suppressing leukocyte chemotaxis.

To confirm the relationship between invading inflammatory cells and enhanced eicosanoid production, it was first 


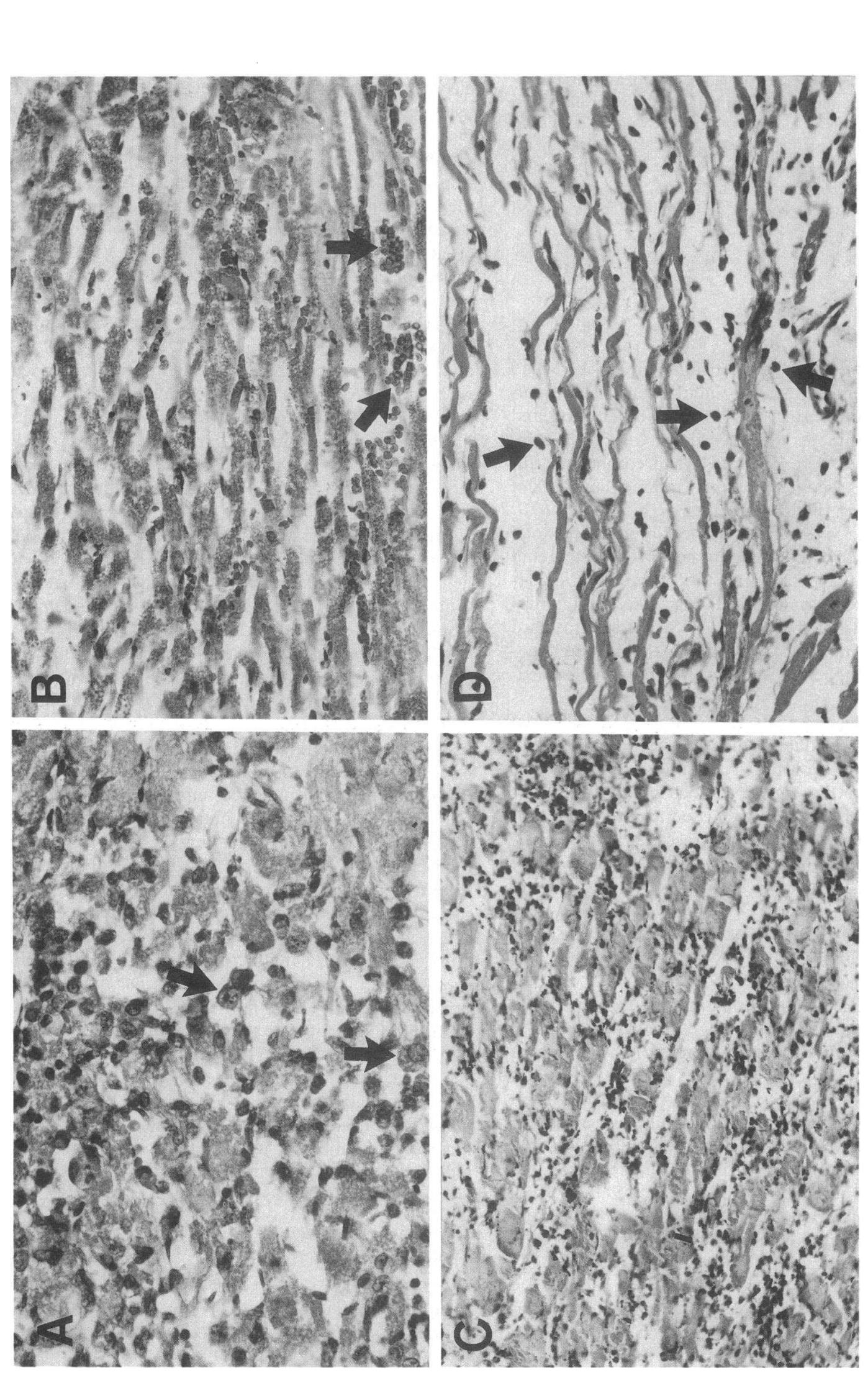

容

צ.

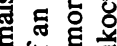
的 焉焉焉 언 菏 ช. 등 은 ठํㅀ I 영

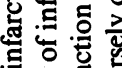

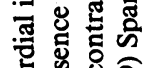
हु 远焉宅 음 क 도웡

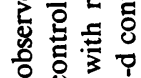

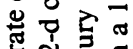
충 E. ․․․․ 옹

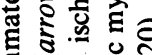
要 音跑 응 릉

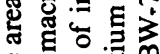

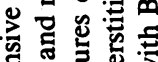
\&

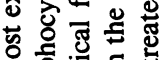
을. 远的 00 \% 言悹突娄

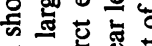

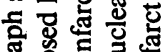
聯政

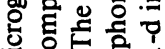
过

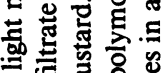
들 语总

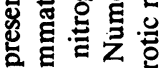
产密记或 ऽ ำ 
Table I. Suppression of Agonist-stimulated Eicosanoid Production following Leukocyte Inhibition into Infarcted Rabbit Hearts

\begin{tabular}{|c|c|c|c|c|c|c|}
\hline & \multicolumn{5}{|c|}{ Isolated heart ( $\mathrm{ng} / 5 \mathrm{~min})$} & \multirow{2}{*}{$\frac{\text { Isolated atria }(\mathrm{ng} / 5 \mathrm{~min})}{\mathrm{TXB}_{2}}$} \\
\hline & $\mathrm{PGE}_{2}$ & 6-keto $\mathrm{PGF}_{1 \alpha}$ & $\mathrm{TXB}_{2}$ & $\mathrm{LTB}_{4}$ & $\mathrm{LTC}_{4}$ & \\
\hline \multicolumn{7}{|l|}{ Basal } \\
\hline Normal (5) & $5 \pm 3$ & $42 \pm 8$ & $<3$ & $<3$ & $<20$ & $1 \pm 0.4$ \\
\hline $1 \mathrm{~d}(5)$ & $37 \pm 8^{\ddagger}$ & $43 \pm 5$ & $6 \pm 2$ & $41 \pm 8$ & $<20$ & $2 \pm 0.6$ \\
\hline $1 \mathrm{~d}+\mathrm{BW} 755 \mathrm{C}(3)$ & $18 \pm 3^{*}$ & $53 \pm 4$ & $3 \pm 1$ & $<3$ & $<20$ & $2 \pm 0.1$ \\
\hline $2 \mathrm{~d}(5)$ & $21 \pm 3^{\ddagger}$ & $62 \pm 20$ & $3 \pm 1$ & $4 \pm 1$ & $<20$ & $3 \pm 0.8$ \\
\hline $2 d+N M(4)$ & $31 \pm 6$ & $73 \pm 26$ & $3 \pm 1$ & $<3$ & $<20$ & $1 \pm 0.3$ \\
\hline \multicolumn{7}{|l|}{ FMLP (100 ng) } \\
\hline Normal & $33 \pm 7$ & $113 \pm 20$ & $30 \pm 9$ & $18 \pm 2$ & $65 \pm 25$ & $18 \pm 4$ \\
\hline $1 \mathrm{~d}$ & $241 \pm 30^{\ddagger}$ & $291 \pm 75^{\ddagger}$ & $88 \pm 7^{\ddagger}$ & $96 \pm 9^{\ddagger}$ & $68 \pm 16$ & $61 \pm 9^{\ddagger}$ \\
\hline $1 \mathrm{~d}+\mathrm{BW} 755 \mathrm{C}$ & $74 \pm 16^{*}$ & $273 \pm 37$ & $44 \pm 6^{*}$ & $16 \pm 3^{*}$ & $59 \pm 20$ & $35 \pm 5^{*}$ \\
\hline $2 \mathrm{~d}$ & $238 \pm 63^{\ddagger}$ & $571 \pm 115^{\ddagger}$ & $161 \pm 34^{\ddagger}$ & $39 \pm 4^{\ddagger}$ & $172 \pm 27^{\ddagger}$ & $63 \pm 6^{\ddagger}$ \\
\hline $2 d+N M$ & $64 \pm 11^{*}$ & $189 \pm 32^{*}$ & $15 \pm 7^{*}$ & $17 \pm 4^{*}$ & $22 \pm 7^{*}$ & $13 \pm 5^{*}$ \\
\hline \multicolumn{7}{|l|}{ BK $(1 \mu \mathrm{g})$} \\
\hline Normal & $30 \pm 5$ & $120 \pm 31$ & $3 \pm 1$ & ND & ND & $2 \pm 1$ \\
\hline $1 \mathrm{~d}$ & $1,111 \pm 106^{\ddagger}$ & $1,407 \pm 238^{\ddagger}$ & $34 \pm 9^{\ddagger}$ & ND & ND & $20 \pm 3^{\ddagger}$ \\
\hline $1 \mathrm{~d}+\mathrm{BW} 755 \mathrm{C}$ & $381 \pm 119^{*}$ & $1,718 \pm 106$ & $15 \pm 2 *$ & ND & ND & $12 \pm 1^{*}$ \\
\hline $2 \mathrm{~d}$ & $1,326 \pm 202^{\ddagger}$ & $4,242 \pm 1,405^{\ddagger}$ & $59 \pm 20^{\ddagger}$ & ND & ND & $32 \pm 7^{\ddagger}$ \\
\hline $2 d+N M$ & $579 \pm 66^{*}$ & $1,597 \pm 407$ & $6 \pm 1^{*}$ & ND & ND & $9 \pm 1^{*}$ \\
\hline
\end{tabular}

1 or $2 \mathrm{~d}$ after in vivo LVMI ( $1 \mathrm{~h}$ of coronary occlusion), ex vivo isolated heart and atrium experiments were performed. Cardiac effluent and atrial bath buffer eicosanoids were measured (RIA) before (basal) and after 5-min stimulations with FMLP (100 ng) and BK (1 $\mu \mathrm{g})$. 1-d infarcted rabbits ( $1 \mathrm{~d})$ and BW-755C treated 1-d infarcted animals (1 d + BW755C) were compared as were control 2-d infarcts (2 d) and nitrogen mustard pretreated 2-d infarcted animals $(2 \mathrm{~d}+\mathrm{NM}$ ). Noninfarcted rabbits (normal) served as a reference to demonstrate enhanced eicosanoid production after LVMI. Leukotrienes were not measured following BK as previous studies failed to demonstrate stimulated release (ND [not determined]). All values are expressed as total nanograms in $5 \mathrm{~min} \pm \mathrm{SEM}$. A two-tailed $t$ test was used to compare infarcted hearts with normal hearts. ${ }^{\ddagger} P<0.05 . t$ test analysis was also used to compare BW755C-treated 1-d infarcts to control 1-d infarcts, and NM-treated 2-d infarcts to control 2 -d infarcts. ${ }^{*} P<0.05$.

necessary to demonstrate that $\mathrm{BW}-755 \mathrm{C}$ would not result in persistent ex vivo enzyme inhibition. Therefore, guinea pig ileum strips were superfused with the coronary venous effluent from a control and infarcted isolated rabbit heart to detect peptidoleukotrienes. As shown in Fig. 3, intracoronary FMLP administration resulted in a dose-dependent contraction of guinea pig ileum, which was inhibited by either intracoronary infusion of BW-755C $(10 \mu \mathrm{g} / \mathrm{ml})$ or superfusion of tissue with

Table II. Suppression of Infarct-stimulated Increase in Right Atrial FMLP Receptor Number following Leukocyte Inhibition

\begin{tabular}{|c|c|c|c|}
\hline \multirow[b]{3}{*}{ Treatment group } & & \multicolumn{2}{|c|}{$\begin{array}{c}B_{\max } \text { (fmol FMLP receptor/ } \\
\mathrm{cm}^{2} \text { right atrial tissue) }\end{array}$} \\
\hline & \multicolumn{3}{|c|}{ Infarction time } \\
\hline & 0 & $1-d$ & $2-d$ \\
\hline Infarct $(n=4)$ & $1.2 \pm 0.1^{*}$ & $12.6 \pm 4.5$ & $14.8 \pm 2.4$ \\
\hline Nitrogen mustard infarct & & $3.2,0.9$ & 1.3 \\
\hline
\end{tabular}

Tissue sections were incubated at $25^{\circ} \mathrm{C}$ in $0.3-1.5 \mathrm{nM}$ concentrations of $\left[{ }^{3} \mathrm{H}\right] \mathrm{FMLP}$ in the presence or absence of unlabeled displacer. $B_{\max }$ values were calculated from Scatchard analysis of binding isotherm data. ${ }^{*} 0-\mathrm{d}$ samples are normal noninfarcted hearts $(n=4)$. Control 1-d and 2-d infarct values represent the mean $\pm \operatorname{SEM}(n=4)$. Individual responses for nitrogen mustard treated 1-d infarcts $(n=2)$ and 2-d infarcts $(n=1)$ are shown. the peptidoleukotriene antagonist FPL-55712 $(0.4 \mu \mathrm{g} / \mathrm{ml})$. After discontinuing the BW-755C infusion, normal contractions in response to intracoronary FMLP were promptly restored, demonstrating rapid and complete washout of BW-755C from cardiac tissue.

To validate the in vivo efficacy of BW-755C following its administration, the ability of $A 23187$ to stimulate whole blood production of $\mathrm{LTB}_{4}$ and $\mathrm{TXB}_{2}$ was used to assess lipoxygenase and cyclooxygenase activity, respectively (Table III). With each animal serving as its own control, BW-755C resulted in a $>70 \%$ reduction in $\mathrm{LTB}_{4}$ production and $55 \%$ reduction in $\mathrm{TXB}_{2}$ synthesis determined 12 and $24 \mathrm{~h}$ postcoronary reperfusion, demonstrating effective cyclooxygenase and lipoxygenase inhibition for the duration of the experiment.

Histology. Histological analysis of 1-d-infarcted rabbit hearts demonstrated transmural myocardial necrosis and prominent reperfusion changes. Inflammatory cell influx consisted almost exclusively of PMNs densely infiltrating infarcted tissue and frequently forming aggregates (Fig. $1 \mathrm{c}$ ). In contrast, $1 \mathrm{~d}$ infarcted hearts from animals receiving BW-755C demonstrated a reduction of inflammatory cell influx into the zone of cardiac injury. PMNs were found sparsely infiltrating necrotic myocardium and rarely forming aggregates (Fig. $1 d$ ). These results are consistent with previous work using BW-755C at $5 \mathrm{~h}$ of reperfusion in experimental canine myocardial infarction (5).

Eicosanoid production. To confirm the relationship between the suppression of acute inflammatory cell invasion and 

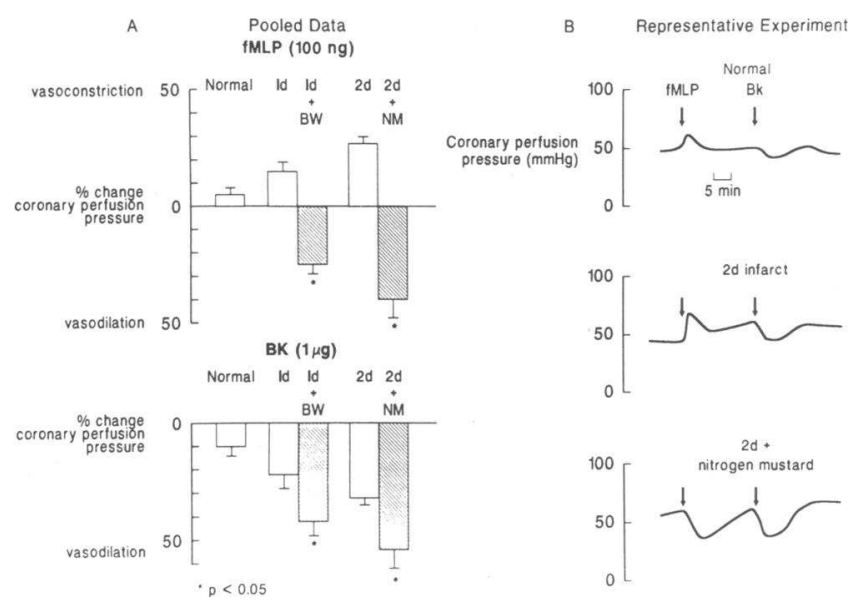

Figure 2. Coronary vascular resistance changes after the inhibition of inflammatory cell influx into ischemic myocardium. $(A)$ Coronary perfusion pressure changes were monitored via a sidearm in the perfusion apparatus and recorded during the intracoronary administration of FMLP $(100 \mathrm{ng})$ or BK $(1 \mu \mathrm{g})$ to ex vivo buffer perfused rabbit hearts previously subjected to in vivo LVMI. All experimental hearts were perfused at a constant flow rate of $25 \mathrm{ml} / \mathrm{min}$ and included noninfarcted hearts (normal), animals convalescing for 1 or $2 \mathrm{~d}$ after coronary artery reperfusion $(1 \mathrm{~d}, 2 \mathrm{~d}), \mathrm{BW}-755 \mathrm{C}$ treated $1-\mathrm{d}$ infarcts $(1 \mathrm{~d}+\mathrm{BW})$, and nitrogen mustard pretreated 2-d-infarcts $(2 \mathrm{~d}$ $+\mathrm{NM})$. Values represent the maximum percentage change in coronary perfusion pressure from baseline following agonist stimulation \pm SEM. No difference in baseline pressures was observed between control and experimental groups. $(B)$ Representative coronary perfusion pressure recordings from a noninfarcted control (normal), a 2-dinfarcted rabbit heart and a nitrogen mustard pretreated 2-d infarct following intracoronary FMLP (100 ng) or BK $(1 \mu \mathrm{g})$. Treatment with nitrogen mustard before coronary artery occlusion results in a reversal of the FMLP-stimulated coronary vasoconstriction and augmentation of the BK-induced coronary vasodilation seen after LVMI

the attenuation of agonist-stimulated eicosanoid production after LVMI, eicosanoid production was quantitated (RIA) from isolated perfused hearts of BW-755C treated, 1-d infarcted animals. As seen in Table I FMLP-stimulation of $\mathrm{PGE}_{2}, \mathrm{TXB}_{2}$, and $\mathrm{LTB}_{4}$ in animals treated with $\mathrm{BW}-755 \mathrm{C}$ was greatly diminished $(69,50,83 \%$ reductions when compared to control 1-d LVMI, respectively). Bradykinin administration to the hearts of BW-755C treated animals also resulted in greatly diminished production of $\mathrm{PGE}_{2}$ and $\mathrm{TXB}_{2}$ (66 and $56 \%$ reduction from controls, respectively). As in the nitrogen mustard experiments, isolated atria from hearts of infarcted rabbits treated with $\mathrm{BW}-755 \mathrm{C}$ demonstrated diminished production of FMLP and BK-induced $\mathrm{TXB}_{2}$ production (43 and $40 \%$ reductions from control 1-d infarcts, respectively [Table I]).

Coronary resistance changes. As in the previous experiments, coronary perfusion pressure was recorded during agonist stimulations. Again, as was observed in the nitrogen mustard treated group, the hearts of animals treated with BW-755C demonstrated a reversal of the FMLP-induced coronary vasoconstriction and augmentation of the BK-induced coronary vasodilation seen after LVMI (Fig. 2).

Enhanced leukotriene production from infarcted myocardium and its relationship to invading leukocytes. To determine whether infarcted myocardium is capable of exaggerated leukotriene biosynthesis, $\mathrm{LTC}_{4}$ and $\mathrm{LTB}_{4}$ production were quan-

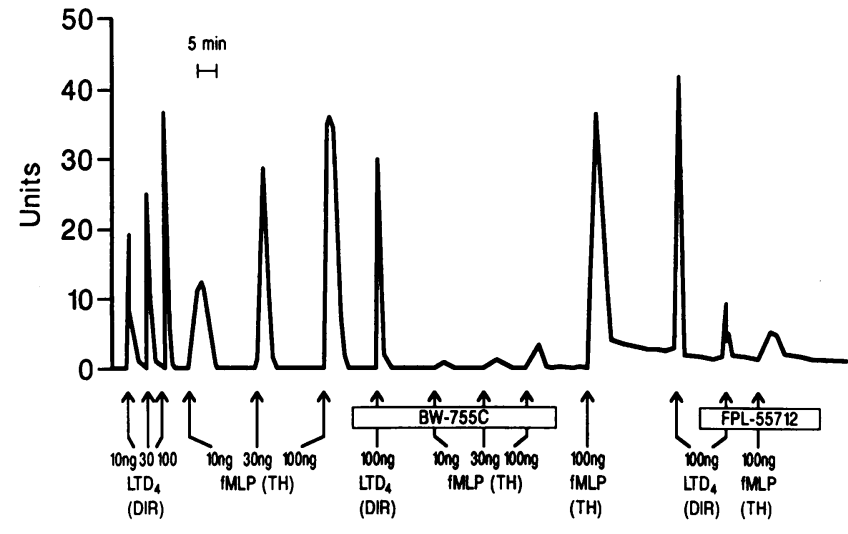

Figure 3. Reversible ex vivo inhibition of cardiac lipoxygenase by BW-755C. A guinea pig ileum strip was suspended under a normal rabbit heart and superfused directly by coronary venous effluent to detect peptidoleukotrienes. Contractions were recorded to authentic $\mathrm{LTD}_{4}$ (standardization), FMLP, and BK administered either directly (DIR) to the tissue or through the heart (TH) in the presence or absence of BW-755C $(10 \mu \mathrm{g} / \mathrm{ml})$, a mixed cyclooxygenase/lipoxygenase inhibitor, or FPL-55712 $(0.4 \mu \mathrm{g} / \mathrm{ml})$, a peptidoleukotriene antagonist.

titated in 1- and 2-d myocardial infarcts. As seen in Table I, infarcted hearts show increases in basal and FMLP-stimulated $\mathrm{LTB}_{4}$ production, as well as in FMLP-stimulated $\mathrm{LTC}_{4}$ production. Peak release of $\mathrm{LTB}_{4}$ was temporally associated with maximal PMN infiltration into the infarct zone as assessed histologically (Fig. 4). Also, exaggerated $\mathrm{LTC}_{4}$ production was found to occur at the time of initial macrophage influx (Fig. 4).

\section{Discussion}

Contribution of invading leukocytes to myocardial infarction. Previous work has shown that after in vivo rabbit LVMI, isolated perfused hearts demonstrate greatly exaggerated prostanoid production in response to stimulation with the chemotac-

Table III. In Vivo Inhibition of Whole Blood Lipoxygenase/ Cyclooxygenase by BW-755C during Myocardial Infarction

\begin{tabular}{|c|c|c|c|c|c|}
\hline & \multicolumn{2}{|c|}{$\begin{array}{l}\text { Pre-infarct/ } \\
\text { Pre-BW755C }\end{array}$} & \multirow[b]{2}{*}{ +A23187 } & \multicolumn{2}{|c|}{$\begin{array}{l}\text { Infarction time }(H) / \\
\text { Post-BW755C }\end{array}$} \\
\hline & $\begin{array}{c}\text { Animal } \\
\text { No. }\end{array}$ & Basal & & $\begin{array}{c}(12) \\
+A 23187\end{array}$ & $\begin{array}{c}(24) \\
+A 23187\end{array}$ \\
\hline & $\mathrm{i}$ & $<4$ & 16 & 6 & $<4$ \\
\hline \multirow[t]{3}{*}{$\mathrm{LTB}_{4}(n g / m l)$} & ii & 5 & 15 & $<4$ & 4 \\
\hline & iii & $<4$ & 19 & $<4$ & 8 \\
\hline & $\mathrm{i}$ & $<5$ & 168 & 112 & 30 \\
\hline \multirow[t]{2}{*}{$\mathrm{TXB}_{2}(n g / m l)$} & ii & 10 & 731 & 340 & 280 \\
\hline & iii & 12 & 515 & 228 & 198 \\
\hline
\end{tabular}

To validate the persistant in vivo inhibition of lipoxygenase and cyclooxygenase enzymes by BW-755C, whole blood eicosanoid production was stimulated by the calcium ionophore A23187 (final concentration $20 \mu \mathrm{g} / \mathrm{ml}$ ) before and after in vivo coronary artery occlusion. Thereafter, plasma $\mathrm{LTB}_{4}$ and $\mathrm{TXB}_{2}$ production were quantitated (RIA) and used as a measure of lipoxygenase and cyclooxygenase activity, respectively. Each animal served as its own control. BW-755C was administered $(25 \mathrm{mg} / \mathrm{kg}$, i.v. $)$ at $1 \mathrm{~h}$ before, and at 8 and $16 \mathrm{~h}$ after surgical LVMI. 


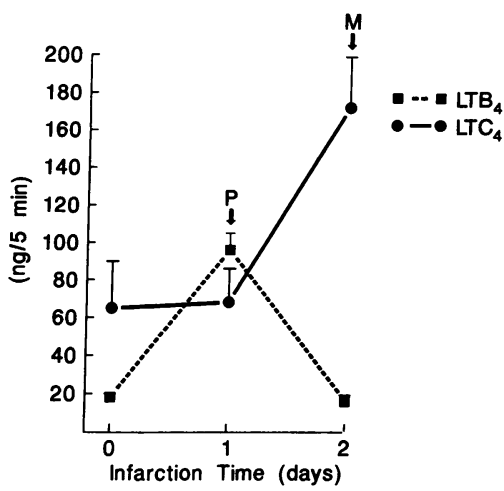

exaggerated $\mathrm{LTB}_{4}$ production and maximal polymorphonuclear leukocyte $(P)$ infiltration as well as $\mathrm{LTC}_{4}$ production and macrophage $(M)$ invasion into the infarct zone.

tic peptide FMLP or BK (1). It is surprising that most of the enhanced arachidonate metabolism was found to occur in the cardiac atria (2), a site remote from the zone of ischemic injury and void of histological evidence of injury or inflammation. Using nitrogen mustard and BW-755C to retard inflammatory cell invasion into developing infarcts, we have shown that both pharmacological manipulations suppress the LVMI-induced augmentation in ex vivo agonist-stimulated eicosanoid production from perfused hearts and isolated atria. Furthermore, both treatments resulted in reversal of the FMLP-induced coronary vasoconstriction and augmentation of the BK-induced coronary vasodilation seen in isolated perfused infarcted hearts.

The mechanism of exaggerated atrial eicosanoid production in response to left ventricular ischemic injury is unknown. Unlike the damaged ventricle, there is no evidence of histological damage or of leukocyte invasion into the atria that exhibits the enhanced eicosanoid metabolite production. One possibility is that exaggerated atrial eicosanoid metabolite production (Table I) may be due to mechanical or neurohumoral consequences of myocardial infarction (e.g., hypertrophy, catecholamines). Continuous isoproterenol infusion results in cardiac hypertrophy and exaggerated BK-stimulated ex vivo prostaglandin production (unpublished data). Suppression of acute inflammatory cell influx in the damaged ventricle may have reduced infarct size as previously shown in canine myocardial infarction models (10), resulting in diminished mechanical and systemic responses influencing the atria and thereby possibly attenuating the LVMI-stimulated increase in eicosanoid metabolite production. Alternatively, a soluble inflammatory cell product may be released from the damaged ventricle into the coronary veins or cardiac lymph and delivered via the systemic circulation to the atria where it may then regulate atrial arachidonate metabolism. As an example of leukocyte mediated cell communication, it has been demonstrated that supernatants from human mononuclear cell cultures induce prostaglandin biosynthesis by stimulating new protein synthesis of dermal and renal cortical fibroblasts $(11,12)$.

Role of leukotrienes in myocardial infarction. Leukotriene production may have a deleterious effect on developing myocardial infarcts $(10,13)$. The present study demonstrates that infarcted myocardium is capable of exaggerated $\mathrm{LTC}_{4}$ and $\mathrm{LTB}_{4}$ production (Fig. 4). It appears that the macrophage is the principal cellular source of enhanced $\mathrm{LTC}_{4}$ production follow- ing LVMI. This is evidenced by the temporal relationship between macrophage accumulation histologically and the development of exaggerated $\mathrm{LTC}_{4}$ production $2 \mathrm{~d}$ after LVMI (Fig. 4). Furthermore, previous studies have shown macrophages possess FMLP receptors (14) and have a prominent synthetic capacity for $\mathrm{LTC}_{4}$ production (15). The enhanced synthesis of this potent coronary artery vasoconstrictor (16) $2 \mathrm{~d}$ after reperfusion suggests a potential role for $\mathrm{LTC}_{4}$ in myocardial infarct extension. Our data also suggest that $\mathrm{LTB}_{4}$ is a chemotactic signal for leukocyte invasion following myocardial infarction in rabbits. Previous studies have shown that $\mathrm{LTB}_{4}$ promotes leukocyte adhesion (17), aggregation, and directed migration (18), and elevated $\mathrm{LTB}_{4}$ levels have been demonstrated in psoriatic skin (19), rheumatoid arthritis articular fluid (20), and ulcerative colitis intestinal mucosa (21). Also, in a model of acute inflammation in mice (intraperitoneal zymosan injection), a causal relationship between $\mathrm{LTB}_{4}$ production and PMN influx has been recently established (22). Our results indicate that: $(a)$ there is increased basal and stimulated production of $\mathrm{LTB}_{4}$ in infarcted myocardium (Table I); $(b)$ this is temporally associated with maximal PMN infiltration (1 d) into the infarct zone (Fig. 4); (c) in vivo inhibition of $\mathrm{LTB}_{4}$ production, as validated by a reduction in ionophore-stimulated whole blood synthesis of this eicosanoid in animals receiving BW-755C (Table III) is associated with a suppression of leukocyte invasion into infarcted myocardium. Furthermore, the concentration of $\mathrm{LTB}_{4}$ released into the coronary effluent from infarcted hearts has been previously shown to induce chemokinesis in rabbit PMNs (23). Collectively, these data suggest that $\mathrm{LTB}_{4}$ is an important proinflammatory mediator during rabbit myocardial infarction.

Potential impact of eicosanoids on cardiac function. A unique finding of our study is the localization of eicosanoid metabolic changes to the atria of infarcted hearts. The unresolved issue is the impact of these changes on atrial function. In the present study, suppression of exaggerated eicosanoid production with nitrogen mustard or BW-755C was associated with a reversal of FMLP-induced vasoconstriction and augmentation of BK-induced vasodilation (Fig. 2). This suggests one potential role for enhanced eicosanoid metabolite production following LVMI, namely, the regulation of coronary artery vasomotor tone and blood flow. Additionally, studies in isolated rabbit hearts suggest that $\mathrm{PGE}_{2}$ and $\mathrm{PGI}_{2}$ may be physiological inhibitors of cardiac sympathetic neurotransmission (23-25). Norepinephrine outflow following sympathetic nerve stimulation and consequent enhanced contractility and heart rate were inhibited by simultaneous infusions of $\mathrm{PGI}_{2}(23)$ or $\mathrm{PGE}_{2}$ (24). Additionally, inhibition of prostaglandin synthesis normally induced by sympathetic nerve stimulation augmented norepinephrine outflow (25).

Our data suggest that $\mathrm{LTB}_{4}$ production following coronary artery occlusion is responsible, at least in part, for leukocyte invasion into the damaged left ventricle. Thereafter, a signal is generated (either as a neurohumeral or mechanical consequence of myocardial infarction, or possibly as a soluble inflammatory cell product) that stimulates atrial eicosanoid metabolite production. Whether these products inhibit sympathetic neurotransmission locally in the atria and thereby exert a protective effect on ischemic tissue by limiting myocardial $\mathrm{O}_{2}$ consumption remains to be determined.

This study extends previous observations to characterize the changes in arachidonate metabolism following the sup- 
pression of inflammatory cell invasion, and identifies a role for invading leukocytes as mediators of exaggerated atrial eicosanoid metabolite production following left ventricular ischemic injury. A further understanding of the relationship between ischemic myocardial injury, leukocyte invasion, arachidonate metabolism, and their effects on organ function may allow for therapeutic manipulation of these factors designed to limit the extent of tissue damage following coronary artery occlusion.

\section{Acknowledgments}

This research was supported by National Institutes of Health Myocardial Ischemia SCOR grant HL-17646 (Dr. Needleman, Dr. Saffitz) American Heart Association grant 86-1099 (Dr. Evers) and National Institute of Health training grant HL-07081 (Dr. Freed).

\section{References}

1. Evers, A. S., S. Murphree, J. E. Saffitz, B. A. Jakschik, and P. Needleman. 1985. Effects of endogenously produced leukotrienes, thromboxane and prostaglandins on coronary vascular resistance in rabbit myocardial infarction. J. Clin. Invest. 75:992-999.

2. Evers, A. S., C. G. Dunkel, J. E. Saffitz, and P. Needleman. 1987. Exaggerated atrial arachidonate metabolism in rabbit left ventricular myocardial infarction. J. Clin. Invest. 79:155-162.

3. Lefkowith, J. B., T. Okegawa, K. DeSchryver-Kecskemeti, and P. Needleman. 1984. Macrophage-dependent arachidonate metabolism in hydronephrosis. Kidney Int. 26:10-17.

4. Okegawa, T., P. E. Jonas, K. DeSchryver, A. Kawasaki, and P. Needleman. 1983. Metabolic and cellular alterations underlying the exaggerated renal prostaglandin and thromboxane synthesis in ureter obstruction in rabbits. Inflammatory response involving fibroblasts and mononuclear cells. J. Clin. Invest. 71:81-90.

5. Mullane, K. M., N. Read, J. A. Salmon, and S. Moncada. 1984. Role of leukocytes in acute myocardial infarction in anesthetized dogs: relationship to myocardial salvage by anti-inflammatory drugs. $J$. Pharmacol. Exp. Ther. 228:510-522.

6. Reingold, D. F., K. Walters, S. Holmberg, and P. Needleman. 1981. Differential biosynthesis of prostaglandins by hydronephrotic rabbit and cat kidneys. J. Pharmacol. Exp. Ther. 216:510-515.

7. Maclouf, J., M. Pradel, P. Pradelles, and F. Dray. 1976. ${ }^{125} \mathrm{I}$ derivatives of prostaglandins. A novel approach in prostaglandin analysis by radioimmunoassay. Biochim. Biophys. Acta. 431:139-146.

8. Lefkowith, J. B., B. A. Jakschik, P. Stahl, and P. Needleman. 1987. Metabolic and functional alterations in macrophages induced by essential fatty acid deficiency. J. Biol. Chem. 262:6668-6675.

9. Spaethe, S. M., M. S. Freed, K. DeSchryver-Kecskemeti, J. B. Lefkowith, and P. Needleman. 1988. Essential fatty acid deficiency reduces the inflammatory cell invasion in rabbit hydronephrosis resulting in suppression of the exaggerated eicosanoid production. $J$. Pharmacol. Exp. Ther. 245:1088-1094.

10. Jolly, S. R., and B. R. Lucchesi. 1983. Effect of BW-755C in an occlusion-reperfusion model of ischemic myocardial injury. Am. Heart J. 106:8-13.

11. Korn, J. H., P. V. Halushka, and E. C. LeRoy. 1980. Mononuclear cell modulation of connective tissue function. Suppression of fibroblast growth by stimulation of endogenous prostaglandin production. J. Clin. Invest. 65:543-554.

12. Jonas-Whitely, P., and P. Needleman. 1984. Mechanism of enhanced fibroblast arachidonic acid metabolism by mononuclear cell factor. J. Clin. Invest. 74:2249-2253.

13. Bonow, R. O., L. C. Lipson, F. H. Sheehan, N. L. Capurro, J. M. Isner, W. C. Roberts, R. E. Goldstein, and S. E. Epstein. 1981. Lack of effect of aspirin on myocardial infarct size in the dog. Am. J. Cardiol. 47:258-264.

14. Synderman, R., and E. J. Fudman. 1980. Demonstration of a chemotactic factor receptor on macrophages. J. Immunol. 124:27542757.

15. Williams, J. D., J. L. Robin, R. A. Lewis, T. H. Lee, and K. F. Austin. 1986. Generation of leukotrienes by human monocytes pretreated with cytochalasin B and stimulated with formyl-methionylleucyl-phenylalanine. J. Immunol. 136:642-648.

16. Tomoike, H., K. Egashira, A. Yamada, Y. Hayashi, and M. Nakamura. 1987. Leukotriene $\mathrm{C}_{4}$ - and $\mathrm{D}_{4}$-induced diffuse peripheral constriction of swine coronary artery accompanied by ST elevation on the electrocardiogram: angiographic analysis. Circulation. 76:480487.

17. Bray, M. A., A. W. Ford-Hutchinson, and M. J. H. Smith. 1981. Leukotriene $B_{4}$ : an inflammatory mediator in vivo. Prostaglandins. 22:212-222.

18. Palmer, R. M. J., R. J. Stepney, G. A. Higgs, and K. E. Eakins. 1980. Chemokinetic activity of arachidonic acid lipoxygenase products on leukocytes of different species. Prostaglandins. 20:411-418.

19. Brain, S., R. Camp, P. Dowd, A. K. Black, and M. Greaves. 1984. The release of leukotriene $B_{4}$-like material in biologically active amounts from lesional skin of patients with psoriasis. J. Invest. Dermatol. 83:70-73.

20. Davidson, E. M., S. A. Rae, and M. J. H. Smith. 1983. Leukotriene $\mathrm{B}_{4}$, a mediator of inflammation present in synovial fluid in rheumatoid arthritis. Ann. Rheum. Dis. 42:677-679.

21. Sharm, P., and W. F. Stenson. 1984. Enhanced synthesis of leukotriene $\mathrm{B}_{4}$ by colonic mucosa in inflammatory bowel disease. Gastroenterology. 86:453-460.

22. Lefkowith, J. B. 1988. Essential fatty acid deficiency inhibits the in vivo generation of leukotriene $\mathrm{B}_{4}$ and suppresses levels of resident and elicited leukocytes in acute inflammation. J. Immunol. 140:228-233.

23. Wennmalm, M., G. A. Fitzgerald, and A. Wennmalm. 1987. Prostacyclin as neuromodulator in the sympathetically stimulated rabbit heart. Prostaglandins. 33:675-691.

24. Hedqvist, P., and A. Wennmalm. 1971. Comparison of the effects of prostaglandins $E_{1}, E_{2}$ and $F_{2 \alpha}$ on the sympathetically stimulated rabbit heart. Acta Physiol. Scand. 83:156-162.

25. Samuelsson, B., and A. Wennmalm. 1971. Increased nerve stimulation induced release of noradrenaline from the rabbit heart after inhibition of prostaglandin synthesis. Acta Physiol. Scand. 83:163-168. 